\title{
AS BIOGRAFIAS DE KÂLIDÂSA
}

\author{
Carlos Alberto da Fonseca
}

Bâna, kavi (poeta) indiano famoso pela composição de dois romances, assim se expressou nos versos introdutórios do seu Harsacarita: (1)

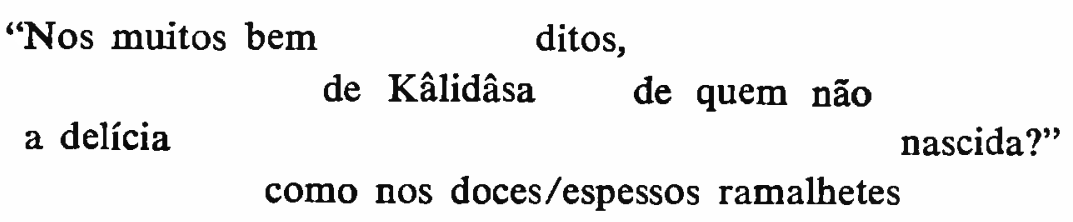

Também Jayadeva, um outro que não o autor do Gitagovinda, assim celebrou Kâlidâsa no início do seu drama Prasannarâghava (2):

$$
\begin{aligned}
& \text { "Bhâsa, a chalaça; } \\
& \text { o mestre dos poetas, }
\end{aligned}
$$

Kâlidâsa, a graça."

Bastam esses dois testemunhos, aclamações feitas por seus próprios pares, para atestar o mérito de Kâlidâsa, "o maior dos poetas indianos" (3), no equilíbrio justo das linguagens do drama e da poesia: todos os estudiosos de literatura sânscrita são unânimes em afirmar, repetindo as palavras de Ingalls, que "ele combina convenção e originalidade, razão e emoção, valores mundanos e valores místicos com bom gosto invariável. Pode-se encontrar cada um desses elemen-

(1) — nirgatâsu na vâ kasya kâlidâsasya sûktisu prîtir madhurasândrâsu mañjarisv iva jâyate/

Apud M. R. KALE - The Ritusamhara. Delhi, Motilal Banarsidass, 1916 (2a. ed., 1967), p. 2. O patrono de Bâna, o rei Harsavardhana, de Thâneswar, viveu entre 606 e $647 \mathrm{~d}$. C.

(2) - bhâso hâsah kavikulaguruh kâlidâso vilâsah/

Apud Sylvain LÉVI - Le théatre indien. Paris, Honoré Champion, 1890 (2a. tiragem, 1963), p. 158. Não há dados sobre a época em que teria vivido esse poeta Jayadeva.

(3) - Arthur A. MACDONELL - A History of Sanskrit Literature. New York, Haskell House, 1900 (reimpr. 1968), p. 10. 
tos separadamente em outros autores sânscritos; mas nenhum outro autor sânscrito percorreu as várias correntes da literatura, perseguiu os vários objetivos da vida humana em tão perfeita harmonia" (4).

Há um aspecto, no entanto, em que não existe unanimidade: o estabelecimento da sua bibliografia e, com redobrado vigor, a tentativa de fixação de sua biografia. Muitas são as hipóteses levantadas - e esse artigo nada mais é que uma coleção dos dados disponíveis, uma preparação do caminho para a apresentação do poeta.

\section{As biografias conjecturais de Kâlidâsa}

A tradição popular indiana afirma que "Kâlidâsa era contemporâneo do rei Vikramâditya, de Ujjayinî. liberal protetor da cultura e das artes" (5) - e isso lhe basta em termos de localização histórica do seu maior poeta: o resto é um conjunto de particularidades, a biografia do poeta. Por outro lado, a ciência indiana moderna e a erudição européia, na ânsia de situar o poeta numa data mais precisa, num tempo mais palpável, descobriram vários Vikramâditya no curso da história da India. Estabeleceu-se, então, um impasse: três elementos - o nome de um rei, o nome duma cidade e uma disposição real - são os pontos de partida para numerosas teorias a respeito da época em que Kâlidâsa teria vivido e, conseqüentemente, para uma coleção disparatada de dados lendários sobre o poeta.

A tradição erudita européia, "ávida de precisão, tentou resolver este problema com a ajuda de dados esparsos, vagos e restritos" (6), no que tem sido seguida mais ou menos de perto pela tradição erudita indiana moderna. Algumas das suas afirmações: a datação do poeta é incerta (7), controversa (8), nada há de definitivo do ponto de vista histórico (9), é muito discutida e a palavra final ainda está por ser dita (10), as circunstâncias da sua vida são incertas (11), tudo é

(4) - Daniel H. H. INGALLS - "Kâlidâsa and the Attitudes of the Golden Age". In Journal of the American Oriental Society, vol. 96, no 1, jan-mar 1976, p. 19.

(5) - C. R. DEVADHAR - Abhijñâna-sakuntalam of Kâlidâsa. Delhi, Motilal Banarsidass, 1934 (3a. reimpr. 1972), p. i.

(6) - LEVI, op. cit., p. 163.

(7) - Vittore PISANI - Kalidasa. Cernusco sul Naviglio, Garzanti, 1946, p. viii.

(8) - Sures Chandra BANERJI - A Companion to Sanskrit Literature. Delhi, Motilal Banarsidass, 1971, p. 49.

(9) - R. H. ASSIER DE POMPIGNAN - Meghadûta/Rtusamhâra. Paris, "Les Belles Lettres", 1938 (2a. tiragem, 1967), p. x.

(10) - KALE, op. cit., p. 2.

(11) - H. de GLASENAPP - Les littératures de l'Inde. Paris, Payot, 1963, p. 159. Trad. do alemão por Robert Sailley. 
desconhecido a seu respeito (12) Victor Henry, em face da "confusão" e da "contradição dos documentos", viu-se quase forçado a acreditar que "esse nome tão célebre () não seria para nós senão um nome" (13)

Por outro lado, se a tradição popular indiana, com a sua certeza histórica, preocupou-se apenas em fixar uma biografia do seu poeta maior cheia de lances novelescos - como se pode ver no item 2 deste artigo -, a tradição erudita indiana e européia, no entanto, assestou os seus instrumentos de observação na tentativa de, com a sua "avidez de precisão", escavar nas camadas históricas da India e delas extrair um quadro confiável onde pudesse situar o poeta. Além disso, e por causa disso, classificou como mito/lenda a "biografia" de Kâlidâsa, pondo, assim, a sua incerteza de quem está distanciado do fato à certeza tradicional popular indiana, que manteve vivos ao longo do tempo a figura e os feitos do poeta. Os pontos em que biografia e lenda coincidem continuam os mesmos: nenhuma teoria coloca em dúvida a cidade de Ujjayinî como cenário da vida do poeta e como capital do império do rei Vikramâditya, e nem o próprio patronato exercido por este último. No entanto, as hipóteses até agora levantadas pela tradição erudita sugerem a colocação do poeta desde o século I a.C. até o século XI d.C. Do exame de todos os dados "esparsos, vagos e restritos" surgem dois Kâlidâsa (e não muitos, como costumam afirmar os estudiosos): o poeta celebrado pela India, em sua concretude biográfica, e o poeta estudado pela ciência, em sua vaguidade lendária.

Esses dois Kâlidầsa sobrevivem em dois suportes narrativos distintos: o primeiro, no texto da memória popular indiana; o segundo, nos textos dos arquivos e dos livros da ciência indiana moderna e ociciental. Os termos "esparsos, vagos e restritos" com que Sylvain Lévi caracterizou os dados de que dispunha até 1890 são, quase cem anos depois, uma falácia: à negatividade das conclusões eruditas, ao deficit no balanço dos dados, persiste a elaboração dum mito ambigüamente concreto e confuso na mente dos estudiosos de Kâlidâsa (exatamente ao contrário da biografia consagrada pela tradição popular): estudar Kâlidâsa é, em primeiro lugar, tentar estabelecer cientificamente a sua data; em segundo, relegar a segundo plano a sua biografia e, para último, a consideração duma compreensão do seu significado e do da sua obra. O que se tenta descobrir, sempre,

(12) - Bernadette TUBINI - Kâlidâsa: la naissance de Kumâra. Paris, Gallimard, 1958, 5a. ed., p. 28.

(13) - Victor HENRY - Les littératures de l'Inde. Paris, Hachette, 1904, p. 215. 
é a que rei Vikramâditya se refere a tradição: tratar-se-ia do rei Vikramâditya que fundou a era Vikrama em 57 a.C.? ou o rei Candragupta II Vikramâditya, da dinastia Gupta, que governou a India de 375 a 415 (14) da era cristã? ou seria um dos muitos Vikramâditya - "o Sol do heroísmo" - que pululam na história da India, tendo-se em vista que o termo não é essencialmente um nome, mas um cognome - "a exemplo de narasimha, ou 'leão dos homens', dado na India durante a Idade Média a todos os reis de Vijayanâgara" (15), reino que floresceu no sul da India depois de já encerrado o período clássico?

Seguem-se, abaixo, algumas das teorias propostas para a datação do poeta Kâlidâsa.

\section{A. A "hipótese Fergusson"}

No ano 544 d. C., um suposto rei Vikramâditya de Ujjayinî expulsou os citas da Índia por ocasião da batalha de Korur. Os seus astrônomos colocaram o início dessa era 600 anos mais cedo: esta é a "hipótese Fergusson" - a "engenhosa hipótese cronológica de Fergusson", como a qualifica Macdonell (16). Segundo ela, o poeta teria vivido no século VI d.C. No entanto, a imaginação moderna insiste, baseada nessa hipótese, em situá-lo no século I a.C., sem perceber que as duas datas são uma só, uma espécie de "fuso horário histórico" Por outro lado, "as pesquisas epigráficas de Fleet destruíram a hipótese de Fergusson. Além disso, parece que nenhum cita poderia ter sido expulso da India ocidental na metade do século VI porque aquela região já havia sido conquistada pelos Gupta mais de cem anos antes" (17) O que faz pensar errado na hipótese Fergusson é a referência aos citas - que de fato estiveram na India no século I a.C., mas não foram expulsos dali por nenhum Vikramâditya.

Assier de Pompignan enumera esta hipótese (18), mas prefere entendê-la como se colocasse o poeta no século I a.C.: "uma era ainda em utilização na Índia traz o nome de Vikramâditya e teve seu ponto de partida no dia em que esse príncipe, na batalha de Kahror, expulsou da Índia os bárbaros que aí estavam estabelecidos. Ela co-

(14) - Datas fornecidas por Romila THAPAR - Historia de la India. I. México, Fondo de Cultura Económica, 1969, p. 432. Trad. do inglês por Carlos Villegas García.

(15) - Angelo de GUBERNATIS - Letteratura indiana. Milano, Hoepli, 1883, p. 70 .

(16) - Op. cit., p. 323.

(17) - Idem, ibidem.

(18) -. Op. cit., p. xi. 
meça no ano 57 antes da era cristã" Em nota a essa última afirmação, lembra que, "segundo o historiador árabe $\mathrm{Al}$ Bêrûni, a batalha de Kahror foi vencida por Vikramâditya em 544 . Fergusson acredita que a origem da era não foi fixada para esta data, mas para 600 anos antes, para 56 a.C., por uma seqüência de considerações de mística numérica: $600=6 \times 100$ ou $60 \times 10$ "

Persistem as objeções explicitadas acima. De qualquer maneira, a única afirmação sólida nesses debates em relação à hipótese Fergusson parece ser o fato de que existiu um Vikramâditya na Índia no século VI - e, então, seria plausível situar aí o poeta.

\section{B. A "hipótese Aihole"}

A inscrição de Pulakeçin II, feita pelo poeta Bâna, em Aihole, em 634 d.C., "atesta a reputação de Kâlidâsa nessa época: o seu autor vangloria-se de ter igualado a glória de Kâlidâsa e de Bhâravi" (19) Pisani argumenta que, "como Bhâravi é, por evidentes motivos estilísticos, posterior a Kâlidâsa, a inscrição não faz senão afirmar que Kâlidâsa não pôde ter vivido depois do século VI" (20) Para Assier de Pompignan, "o romancista Bâna, que pode ser fixado com bastante certeza na primeira metade do século VII, menciona Kâlidâsa com elogios no seu Harsacarita" (21) Glasenapp concorda com estas afirmações: "Dado que Kâlidâsa é citado por Bâna e na inscrição de Amole como um poeta eminente, ele deve ter vivido antes do século VII d. C." (22) — com quem também está de acordo Sylvain Lévi (23)

\section{A "hipótese Daçapura"}

Além desta inscrição de Aihole, os estudiosos lembram a existência duma outra, de 473 d.C. (24), escrita pelo panegirista Vatsa-

(19) - ASSIER DE POMPIGNAN, op. cit., p. xii. V. também BANERJI, op. cit., p. 49 O texto da inscrição é o seguinte:

yenâyoji na veçma sthiram arthavidhau vivekinâ jinaveçma/ sa vijayatâm ravikîrti $h$ kavitâçritakâlidâsabhâravikîrti $h$ /

("Por quem de discernimento não se sustentava a casa, a casa de vencedor, regiamente, na lei da recompensa? Que os dois resplandeçam: glória do Sol: a glória Kâlidâsa e Bhâravi, consumados na poesia"), citado por M. R. KALE - Kiratârjunîyam, cantos I-III. Delhi, Motilal Banarsidass, 1966 reimpr. 1977), p. xix.

(20) - Op. cit., loc. cit.

(21) - Op. cit., p. xii.

(22) - Op. cit., p. 159

(23) - Op. cit., p. 165.

(24) - Data fornecida por GLASENAPP, op. cit., p. 159, e por MACDONELL, op. cit., p. 320. 
bhatti no templo do Sol em Daçapura (atual Mandasor) Pisani lembra que Bühler afirma que o texto dessa inscrição imita versos de Kâlidâsa (25); lembra, ainda, que Kielhorn e o mesmo Bühler reconheceram neles "a imitação de versos kâlidâsianos, principalmente do Rtusamhâra: mas esse fato não é tão inexpugnável, entre outras razões porque a atribuição do Rtusamhâra ao nosso poeta não foi admitida de todo" - o que complica um pouco mais a questão. Mas Glasenapp afirma que, se aceitar a afirmação de Bühler que ele refere, "a metade do século V seria o terminus ad quem" (26).

\section{A "hipótese Oxus"}

Ingalls levanta uma outra série de motivos (27): "A data aproximada de Kâlidâsa (400-450 d.C.) é dada por sua referência aos hunos, no Raghuvamça IV. 67), que estariam vivendo no rio Oxus como o interpreta Vallabhadeva, o seu mais tardio comentador" Esse argumento foi recusado sob a alegação de que a interpretação $v a n k s u$ (Oxus) naquela passagem não é correta, pois os primeiros comentadores interpretaram o termo como sindhu.

Em relação a essa questão - pelo fato de não possuirmos nenhuma edição em Sânscrito do Raghuvamça —, o que parece ocorrer é na verdade uma incompreensão da diferença entre "leitura" e "interpretação" Se no texto se "lê" sindhu, nada obsta que Vallabhadeva o "interprete" como vanksu. Deve-se lembrar, para tanto, que o termo sindhu significa, simplesmente, "rio", e dele se originou o termo Indo que hoje designa o sindhu em cujas margens se desenvolveu a cultura védica. Segundo Monier-Williams (28), vanksu é "um braço ou afluente do rio Ganges"; designa, no Mahâabhârata, o rio Oxus; nos Purâna, comparece sob a forma vaksu. Fica claro, então, que o que se lê como sindhu na estrofe em tela pode, como o interpretou Vallabhadeva, ter sido o sindhu de nome vanksu (Oxus) Em outras palavras, a informação de Monier-Williams abona a argumentação de Ingalls, pois que o termo $v a n k s u$ (e o objeto que ele designa) só se tornou conhecido dos indianos quando da conquista do Leste, fixando-se na memória de todos ao tempo da elaboração do Mahâbhârata e dos Purâna de maneira que uma referência a um determinado sindhu, no contexto daquela parte do Raghuvamça, só poderia dizer respeito ao sindhu de nome $V a$ n $k$ su.

(25) - Op. cit., p. ix.

(26) - Op. cit., loc. cit.

(27) - Op. cit., p. 15.

(28) - Sanskrit-English Dictionary. Oxford, Clarendon Press, 1974 (reimpr. da 1a. ed., de 1899), s. v. vanksu. 
No entanto, não havia sido essa a intelecção anterior à argumentação dc Ingalls (e à medida que agora se lhe dá). Carlo Formichi assim traduz a estrofe IV. 67 (29): "E os cavalos deles [dos hunos], eliminada a fadiga da caminhada, voltando para as margens do Sindhu, sacudiam as crinas às quais se aderia o açafrão" Em nota à estrofe seguinte afirma que "os hûna do texto são evidentemente os hunos ou indo-citas que se estabeleceram no Panjab e ao longo do Indo no início da nossa era" Não traduzindo Sindhu (que, no contexto, não é nome próprio, mas apenas a indicação de um mero acidente geográfico) por "rio", a tradução corre o risco de situar o relato nos tempos em que os hunos esiavam estabelecidos no Panjab (do qual faz parte o rio Indo - ou o rio Sindhu - ou o sindhu Sindhu) e não na etapa seguinte da conquista, em que os hunos chegaram ao rio Oxus - ou rio Vanksu - ou sindhu Vanksu: isso porque a utilização do termo Sindhu como designativo de um rio está comprometida com a designação do rio Indo. A nota que Formichi acrescenta tem razão quanto à evidência, mas é um pouco canhestra no seu desenvolvimento: é certo que se trata dos "hunos ou indo-citas que se estabeleceram no Panjab e ao longo do Indo no início da nossa era" - mas o contexto da estrofe não diz respeito a essa primeira invasão, e, sim, àquela que foi perpetrada durante o governo da dinastia Gupta - ao tempo de Kâlidâsa .

Ingalls, no entanto, estabelece argumentação nova e, nesse sentido, para nós decisiva: "A objeção não afeta o terminus a quo. Kâlidâsa certamente vira os hunos com os seus próprios olhos: não podemos supor que ele os tivesse visitado na Sibéria onde viviam antes da conquista da Báctria no início do século V Além disso, a objeção não pode colocar Kâlidâsa muito depois. Por volta de 510 os hunos destruíram Ujjayinî, que Kâlidâsa descreve como uma cidade florescente. A interpretação $v a n k s u$ (ou $v a n k s u$ ), sem dúvida, é correta"

\section{E. A "hipótese Dinnâga-Nicula"}

Na estrofe 14 do Meghadûta comparece o termo dinnâga, que designa os elefantes míticos que guardam os pontos cardeais - e assim o termo comparece nas traduções ocidentais do poema; aconteceu que Daksinavartanâtha e Mallinâtha, comentadores do poema de Kâlidâsa, interpretaram o termo como uma referência a um certo sábio budista, adversário do poeta, que teria esse nome. Na mesma estrofe figura o termo nicula, designação do caniço da espécie Calamus rotang; sucedeu, porém, que o mesmo comentador Mallinâtha reconheceu nesse termo uma alusão a Nicula, um companheiro de estudos de Kâlidâsa

(29) - Kalidasa: la stirpe di Raghu. Milano, Instituto Editoriale Italiano, s. d., p. 86 . 
que havia refutado as críticas anteriores feitas às obras do poeta (30) A verdade é que, segundo os registros históricos budistas, existiu de fato um sábio budista com o nome de Dinnâga no século VI; a contracrítica de Nicula, porém, não chegou a ser consignada em papel. Até aqui, as considerações de Assier de Pompignan (31), que afirma, também, que "essa alusão a Dinnâga não se encontra nos comentários de Vallabhadeva nem nos de Sthiradeva, sensivelmente anteriores a Mallinâtha" Keith recusa-se a aceitar a alusão ao adversário de Kâlidâsa (32), afirmando que Dinnâga "não deve ser posterior ao ano 400" - o que colocaria o poeta, no máximo, no século IV d. C. Já Sylvain Lévi afirma (33) que "a menção equívoca de Nicula e Dinnâga no Meghadûta, se se seguir a interpretação de Mallinâtha, recoloca o poeta no século VI"

\section{F. A "hip'ótese Kumâradâsa"}

Sylvain Lévi (34) traz à baila a tradição cingalesa que rememora a viagem de Kâlidâsa ao Ceilão e sua morte naquela ilha, durante o reinado de Kumâradâsa, no ano 522 da era cristã. Afirma que "a lenda está citada como muito conhecida já no Poerakum Bâ Sirit, obra cingalesa do século XIV" (35) Assier de Pompignan ressalta que essa tradição "merece a confiança da história em mais dum ponto guinte:

(30) - O conteúdo dos dois versos finais da estrofe em questão é o sesthânâd asmât sarasaniculâd utpatodanmukhah kham dinnâgânâm pathi pariharan sthûlahastâvalehân/,

que ASSIER DE POMPIGNAN, op. cit., p. 6, traduz da seguinte maneira: "Deixa este lugar que o caniço pleno de seiva cobre e voa pelos ares, para o Norte, evitando no caminho os rudes contatos da tromba dos elefantes que guardam os pontos cardeais", apresenta, também, o comentário de Mallinâtha: "Ele [Kâlidâsa] faz entender aqui, por alusão, outro sentido: Deste lugar, onde se encontra [um grande poeta de bom gosto (rasika, "cheio de gosto = sarasa, "plano de seiva"), chamado] Nicula, [companheiro de estudos de Kâlidâsa e que refutara as críticas anteriormente feitas às obras desse último], sai tu de cabeça erguida (unnatamukha "a cabeça erguida" = udanmukha "de face para o Norte") [pelo fato de não seres reprovável]; evitando no caminho [o caminho da eloquência (sârasvata, "eloquência" e "de Sarasvatî")] as injúrias da mão [que consistem em violências manuais; (hasta, "tromba" e "mão") avaleha significa "orgulho, impureza, injúria" segundo Viçva] dos Dinnâga [plural de dignidade: do doutor Dinnâga, adversário de Kâlidâsa]"

(31) - Op. cit., pp. xii e 6.

(32) - A. Berriedale KEITH - A History of Sanskrit Literature. London, Oxford University Press, 1920 (reimpr. 1961), p. 81

(33) - Op. cit., pp. 164-165.

(34) - Op. cit., p. 165.

(35) - Sylvain LÉVI lembra, ainda, à p. 35 do Apêndice, que BENDALL, in Journal of the Royal Asiatic Society, jan 1888, p. 440, dá o título de duas obras modernas fundamentais para essa tradição: The Historical Tragedy entitled Kalidas, de Simon da Silva Seneviratna, e Kalidas Charitaya, um poema em 255 estrofes - ambas publicadas em Colombo em 1887. 
de vista" (36); já Ingalls, que coloca o poeta decididamente entre os anos 400 e 450 , afirma categoricamente que "é inaceitável a tradição da visita de Kâlidâsa ao rei Kumâradâsa do Ceilão" (37) Por outro lado, Glasenapp salienta que "a tradição faz do autor do Jânakiharana, Kumâradâsa, um rei do Ceilão, um amigo de Kâlidâsa, mas ele pertence sem dúvida apenas ao século VII d.C." (38); para Banerji, no entanto, que se baseia na tradição cingalesa, Kumâradâsa viveu entre 517 e 526 d.C. (39)

\section{G. A "hipótese Bhartrhari"}

Lembra Sylvain Lévi ainda uma outra hipótese a favor da colocação de Kâlidâsa na primeira metade do século VI (40) Recorda a data do poeta Bhartrhari, que afirma ter morrido entre 652 e 655 . O seu mestre, Vasurâta, mantivera com Vasubandhu uma controvérsia sobre questões gramaticais, durante o reinado de Bâlâditya, filho do rei Vikramâditya. Bhartrhari, nascido no final do século VI, estaria separado por duas gerações do grande Vikramâditya que a tradição afirma ser o protetor de Kâlidâsa. E apresenta o seguinte esquema:

"Bhartrhari, morto \pm 652 ,

discípulo de

Vasurâta, contemporâneo e cunhado do Bâlâditya, filho de

Vikramâditya" (41).

Esse Bâlâditya, segundo Keith (42), é o mesmo Gupta que, aliado a Yaçovarman, um grande governante da India Central, expulsou os

(36) - Op. cit., p. xii.

(37) - Op. cit., p. 15.

(38) - Op. cit., p. 167 PISANI, op. cit., p. viii, depois de relatar a lenda da morte da Kâlidâsa, lembra que a estrofe completada pelo poeta é, na verdade, a vigésima do Çrngâratilaka. Acrescenta, ainda, que uma crônica do Ceilão afirma que o rei, grande amigo de Kâlidâsa, atirou-se ao fogo que consumia o cadáver do poeta. Em nota, afirma que essa história é contada de modo diferente no Kathâsaritsâgara (antologia de contos de inspiração jinista, composta em Ahmedabad em 1600), de Hemavijaya, novela 53, onde também é diferente a estrofe completada pelo poeta.

(39) - Op. cit., p. 62.

(40) - Op. cit., pp. 35-36, Apêndice.

(41) - A fonte em que se baseia esta hipótese é o relato escrito entre 692 e 695 da viagem que o peregrino chinês Yi-Tsing fez à Índia. Nele o viajante conta a vida de Bhartrhari e que o poeta havia morrido há 40 anos; in ASSIER DE POMPIGNAN, op. cit., pp. xi-xii.

(42) - Op. cit., p. 74. 
hunos em 528. Mas, se se atenta para a sequiência dos dinastas Gupta, percebe-se que Bâlâditya não foi o sucessor nem de Candragupta II nem de Kumâragupta I, ambos cognominados Vikramâditya - o que confere à argumentação de Sylvain Lévi o mero caráter de hipótese.

\section{H. A "hipótese Gupta"}

A alusão aos Gupta coloca o problema da datação de Kâlidâsa num conjunto de dados de outra natureza - alguns mais bem definidos e referendados pela tradição, e outros, absolutamente confusos.

Consciente do esplendor cultural alcançado pela India durante o governo de Candragupta II, cognominado Vikramâditya, a tradição não hesita em identificá-lo ao Vikramâditya que foi o protetor de Kâlidâsa. O fato de Prabhâvatîguptâ, filha do rei, ter-se casado com um príncipe Vâkâtaka reforça a identificação, pois o fato faz parte da biografia do poeta (43)

Por outro lado, o seu filho e sucessor, Kumâragupta I, que governou de c. 415 a 454, foi cognominado Vikramâditya e Mahendrâditya. O primeiro destes termos é suficiente para identificá-lo ao protetor de Kâlidâsa. Já a consideração do segundo cognome interpõe algumas complicaçốes. Afirma Devadhar (45) que, "de acordo com o Kathâsarisâgara 18.59-60, o pai de Vikramâditya era Mahendrâditya" Bem, se o Vikramâditya destes contos for realmente Kumâragupta, então seu pai - Candragupta II - seria Mahendrâditya: nome ou cognome, nenhum é adotado por nenhum estudioso.

Mas a discussão em relação a esses cognomes é um pouco mais complicada. Shembanevkar (46) esclarece que "a teoria Gupta se baseia na afirmação de que Candragupta II foi o primeiro monarca a adotar o título Vikramâditya, ao passo que, segundo o testemunho das crônicas Rajput e do Kathâsaritsâgara, o primeiro rei a adotá-lo foi o rei Vikramâditya da dinastia Paramâra, herói de incontáveis lendas, governantes de Ujjayinî à época de Kâlidâsa" Pode-se perceber, no entanto, que qualquer confusão é puramente artificial: existem, na verdade, dois grupos de personagens pertencentes a duas dinastias di-

(43) - No terreno científico, a "teoria de que Kâlidâsa foi enviado por Candragupta II à corte Vâkâtaka onde ele se tornou tutor de Pravarasena, filho de Prabhâvatîguptâ" foi proposta por K. S. RAMASWAMI SHASTRI "a partir de referências literárias do século $X$ e dum comentário de Râmadâsabhûpâla (1595) sobre o Setubandha" no Seventh All India Oriental Conference em 1935; texto publicado nos anais desse Congresso, pp. 98-108; apud INGALLS, op. cit., p. 15.

(44) - THAPAR, op. cit., p. 174

(45) - Op. cit., p. iii.

(46) - Apud DEVADHAR, op. cit., pp. ii-iii. 
ferentes - embora seja sugerido que ambas tenham governado Ujjayinî na mesma época, na época de Kâlidâsa. Uma delas, a dinastia Gupta, apresentar-se-ia, em relação ao período em questão, da seguinte maneira: Candragupta II (cognominado Vikramâditya) foi sucedido por seu filho Kumâragupta I (Vikramâditya e Mahendrâditya) $\mathrm{Na}$ outra, a dinastia Paramâra, a ordem seria a seguinte: a Mahendrâditya sucedeu seu filho Vikramâditya .

Deve-se confrontar esse quadro com outro argumento: o de que haveria, incrustradas nos títulos de duas obras do poeta, alusões ao seu rei: no título do poema épico Kumârasambhava uma referência a Kumâragupta, jovem que haveria de herdar o trono; no do drama Vikramorvaçîya, uma insinuação do seu cognome, o trono já herdado. Os cronólogos da obra de Kâlidâsa, no entanto, são unânimes em informar que o Vikramorvaçîya é anterior ao Kumârasambhava o que configuraria uma acronicidade: louvar primeiro o Kumâraguptarei para depois louvar o Kumâragupta-príncipe. E possível, no entanto, que o Vikramorvaçîya tenha sido escrito por ocasião do retiro de Candragupta II (Vikramâditya) da vida ativa e da coroação de Kumâragupta I (Vikramâditya) como rei e que no título Kumârasambhava esteja mesmo embutida uma alusão a Kumâragupta-rei.

É importante, ainda, ressaltar as formulações de Vincent Smith (47), segundo as quais Kâlidâsa deve ter vivido sob dois ou mais Gupta: "as primeiras obras de Kâlidâsa foram compostas antes de 413, durante o reinado de Candragupta; as últimas, sob Kumâragupta; talvez a sua carreira se tivesse estendido, já próximo da sua morte, ao reinado de Skandagupta" (48) Devadhar lembra, ainda, que alguns estudiosos, baseando-se na referência que o poeta faz à conquista crescente da Índia pelos hunos, no Raghuvamça, afirmam que Kâlidâsa deve ter vivido depois da derrota que Skandagupta lhes infligiu - o que estaria de acordo com os cronólogos da obra de Kâlidâsa: o Raghuvamço é, segundo eles, posterior ao Vikramoryaçîya. Deve-se notar, também, que Assier de Pompignan afirma que "Skandagupta também adotou o título de Vikramâditya" (49) E, nesse sentido, ele não está sozinho. Margaret e James Stutley (50) salientam que os termos -âditya e -anka surgem, na Índia, como elementos participantes de cognomes reais, a partir da entrada dos Gupta na história

(47) - Apud C. R. DEVADHAR - Mâlavikâgnimitram of Kâlidâsa. Delhi, Motilal Banarsidass, 3a. ed. (reimpr. 1977), p. ii.

(48) - “(. ) 467 é a última data relacionada a Skandagupta” In THAPAR, op. cit., p. 174.

(49) - Op. cit., p. xii .

(50- - Margaret STUTLEY e James STUTLEY - A Dictionary of

Hinduism. London, Routledge-Kegan Paul, 1977, s. v. vikramâditya. 
indiana: "Candragpta II (376-414) assumiu o título de Vikramâditya, seu filho Kumâragupta I (414-455) o de Mahendrâditya, seu filho e sucessor Skandagupta (455-467) o de Kramâditya ou Vikramâditya, e os continuadores da dinastia continuaram essa prática" Também Monier-Williams documenta o uso posterior do cognome: ele foi usado também pelo rei Bhoja (ou Bhojadeva), celebrado rei de Dhârâ, grande protetor do saber no início do século XI e autor de muitas obras (51).

\section{A "hipótese navaratna"}

A referência aos Gupta atende a outro fato da biografia de Kâlidâsa: o de ele ter integrado as navaratna, as "nove gemas" intelectuais da corte de Vikramâditya - "embora esta lenda seja suspeita" para Sternbach (52) Este estudioso nada afirma a respeito da suspeição contra a (assim sempre referida) lenda; a suspeita, porém, pode ser explicada se o bloco de intelectuais for visto por outro prisma.

E muito comum os estudiosos considerarem como contemporâneas todas as Nove Gemas. Esse bloco, porém, é bastante heterogêneo em termos de datação. Dhanvantari (53), autor dum glossário médico, era mais velho que Amarasimha, um lexicógrafo, que era, por sua vez, mais novo que Kâlidâsa, a quem citou em sua obra; Ghatakarpara, poeta, era contemporâneo de Kâlidâsa e comparece em sua biografia; Narâhamihîra, astrônomo, viveu no século VI ("escreveu depois de 505 e morreu em 587" (54); Vararuci, poeta, costuma ser citado como um dos ornamentos da corte do rei Bhoja, no século XI; Ksapanaka (lexicógrafo), Vetâlabhatta e Çanku (poetas) são nomes sem maiores referências. A não ser que se entenda "mais velho" e "mais novo" como alusões às respectivas idades de Dhanvantari e Amarasimha dentro do mesmo momento cronológico em que viveram Kâlidâsa e seu contemporâneo Ghatakarpara, o conjunto - salvo talvez Ksapanaka, Vetâlabhatta e Çanku - revela-se distribuído ao longo de seis séculos a menos que se diga algo de mais decisivo sobre o fato de o rei Bhoja também ter adotado o cognome de Vikramâditya (ver acima)

E por essa razão que, a nosso ver, as navaratna não formariam um bloco único e sincrônico de letrados a serviço e sob a proteção de "um certo rei Vikramâditya": talvez seja produtivo pensar no número

(51) - Op. cit., s. v. vikramâditya e bhoja.

(52) - Ludwig STERNBACH - "A propos de petits recueils de vers gnomiques" In Journal Asiatique, tomo CCLXII, 1974, fasc. 3/4, p. 391.

(53) - Salvo outras indicações, os dados relativos às Nove Gemas foram extraídos de KEITH, op. cit., p. 76.

(54) - LEVI, op. cit., p. 165. 
"nove" como a somatória progressiva e final de "gemas" que fossem sendo acrescentadas pelos sucessivos Vikramâditya Gupta a um tesouro intelectual que se fizesse aos poucos conforme o mérito e o prestígio do artista ou cientista.

\section{J A "hipótese jâmitra"}

Há ainda o argumento de que "o emprego pelo poeta de idéias e termos astronômicos emprestados aos gregos, e cuja história é possível seguir na India, recoloca Kâlidâsa antes da primeira metade do século IV" (55) A questão é levantada em relação ao uso do

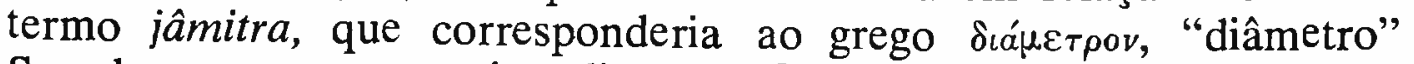
Sucede que os gregos invadiram a India no século IV a.C. e, a exemplo de outros termos (âpoklima, gr ámox $\lambda_{\mu} \mu_{a}$, "desvio"; harija,

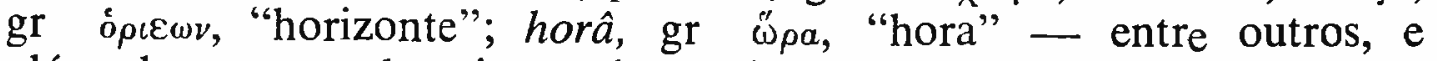
além dos nomes dos signos do zodíaco), o termo jâmitra é "termo que foi emprestado ao grego e conservou a significação especial que possuía nas obras dos astrônomos alexandrinos" (56)

Em relação a este mesmo termo, no entanto, verifica-se - com um exame do Sanskrit-English Dictionary de Monier-Williams que ele foi usado, pelos poetas indianos, apenas por Kâlidâsa, no Kumârasambhava VII.1. e também por Varâhamihîra, astrônomo, em três obras: Varâhamihîrabrhajjâtaka, Varâhamihîrabrhatsamhitâ e Laghujâtaka - três tratados de astronomia. Mas o significado abonado por Monier-Williams para esses usos não é o de "diâmetro", mas o de "sétima mansão lunar" O que foi emprestado do grego foi apenas a forma do termo, mas não o seu significado: para "diâmetro", os únicos termos abonados pelo mesmo Monier-Williams, desta feita no seu English-Sanskrit Dictionary (57), são vyâsa, viskambha, vistrti — todos ligados à idéia de "extensão, medida" e ao conceito "diâmetro de um círculo" Não se percebe claramente como o termo jâmitra teria sido emprestado ao grego e conservado a "significação especial que possuía nas obras dos astrônomos alexandrinos", pois que os indianos já possuíam os seus termos para a idéia de "diâmerto dum círculo": vyâsa já aparece com esse significado nos çulvasûtra, tratados que contêm regras exatas para a medida e a construção do local para o sacrifício e para os altares do fogo védico (58). Se,

(55) - Idem, ibidem, p. 164.

(56) - Goblet d'ALVIELLA - Ce que l'Inde doit à la Grèce. Paris, Paul Geuthner, 1926, p. 79.

(57) - Delhi, Motilal Banarsidass, 1851 (reimpr. 1956), s. v. diameter.

(58) - BANERJI, op. cit., p. 336. 
nesse caso específico, devem alguma coisa ao grego, é apenas o molde do decalque efetuado e ao qual se acoplou um significado ausente do termo grego.

Essa argumentação, no entanto, não impede que Kâlidâsa possa realmente ser situado no século IV - não pelo uso em si do termo jâmitra, mas pelo fato de que a aclimatação do vocábulo no léxico (astronômico ou não) indiano permitia fosse ele utilizado por qualquer poeta em qualquer época posterior à penetração grega na India - sem que por isso o autor deva ser colocado necessariamente no século IV.

\section{K. A "hipótese Bhoja"}

Vallâla, um autor que viveu no final do século XVI, escreveu o Bhojaprabandha, uma obra em prosa, no qual relata o relacionamento de Bhoja (aparentemente o rei Bhoja, de Dhârâ) com os muitos poetas filiados à sua corte por seu patronato liberal. Afirma Banerji (59), no entanto, que a obra "é inútil como documento histórico. Desatenta à cronologia, coloca juntas na corte de Bhoja figuras literárias tais como Kâlidâsa, Bhavabhûti, Dandin, Mâgha e outros poetas menos conhecidos" Para o mesmo estudioso, Mâgha talvez tenha vivido no século VII, Bhavabhûti viveu na segunda metade do século VII ou na primeira metade do século VIII; e, Dandin, na primeira metade do século VIII.

Bhoja não era Gupta; entretanto, adotou o título de Vikramâditya - fato que, por si só, é suficiente para a tradição o identificar ao patrono de Kâlidâsa. Por outro lado, este rei viveu no século XI, e, tendo-se em vista outras "figuras literárias" que animam a narrativa dos atos da sua corte, nada autoriza a afirmar que elas seriam parte das navaratna abonadas pela tradição.

Banerji, como se viu acima, não dá credibilidade histórica à obra. Em termos ocidentais, talvez a fonte da hipótese seja uma série de artigos por Théodore Pavie no Journal Asiatique (60) nos quais o seu autor nada mais faz que referendar a fantasia de Vallâla.

\section{A "hipótese Açvaghosa"}

Talvez contemporâneo de Kaniska (rei kusana que subiu ao trono por volta de 78 d.C. no noroeste da Índia), Açvaghosa - filho de um brâmane, que adotou o Budismo e talvez pertencesse à seita

(59) - Idem, ibidem, p. 160.

(60) - "Bhôdjaprabandha, histoire de Bhôdja, roi de Malva et des pandits de son temps": vol. 3, 1854, pp. 185-230; "Le poëte Kâlidâsa à la cour de Bhodja, roi de Malva (Extrait du Bhôdjaprabandha du pandit Bellal)": vol. 4, 1854, pp. 385-431; "Les pandits à la cour du roi Bhôdja": vol. 5, 1855, pp. 76-105. 
Hînâyana (61) — escreveu o Buddhancarita "no estilo artificial [sic] e o classificou com mahâkâvya"' (62) - gênero de poesia de corte que, de acordo com o Mahâbhâsya de Patañjali, se originou antes do começo da nossa era e continuou a ser cultivado nos séculos seguintes (63)

O que traz Açvaghosa para o conjunto das conjecturas a respeito da datação de Kâlidâsa é o fato de que, "em relação a esse escritor, é interesante observar que há uma estreita semelhança entre a sua poesia e a poesia de Kâlidâsa. Não só existe um íntimo paralelismo entre algumas passagens e descrições isoladas, mas também entre idéias e expressões regularmente distribuídas ao longo do poema" (64) - o que faz R. N. Apte afirmar que, à vista dessas semelhanças, "um dos poetas está usando o outro" (65) Afirma Devadhar que se deve lembrar que "Açvaghosa é primeiramente um filósofo e, depois, um poeta; ao passo que Kâlidâsa é um poeta original. E provável, então, que Açvaghosa seja o que toma emprestado e Kâlidâsa, o seu original" (66) — o que situaria nosso poeta ao redor do ano zero da era cristã .

A conclusões muito diferentes chega Keith, com afirmações tais como: "Kâlidâsa exibe nos seus dramas a influência de um desenvolvido refinamento de estilo e, nos seus poemas épicos, normalmente se afasta das características corriqueiras fáceis de serem encontradas nos poemas épicos de seu precursor Açvaghosa" (67); "o patronato de Kaniska produziu a primeira grande obra dos épicos de corte preservada até nós, o Budhacarita de Açvaghosa" (68); "o prácrito dos dramas de Kâlidâsa é decididamente posterior ao de Açvaghosa" (69); e "há, aqui e al", no Kumârasambhava, recordações inegáveis de Açvaghosa, como na descrição das mulheres da cidade à chegada de Çiva e Pârvatî, que tem um protótipo na descrição do Buddhacarita da

(61) - BANERJI, op. cit., p. 17

(62) - DEVADHAR, Abhijñânasakuntalam, p. ii.

(63) - Idem, ibidem.

(64) - Idem, ibidem.

(65) - Apud DEVADHAR, idem, ibidem.

(66) - Idem, ibidem.

(67) - KEITH, op. cit., pp. xv-xvi.

(68) - Idem, ibidem, p. 54.

(69) - Idem, ibidem, p. 55. 
entrada do príncipe Sarvârthasiddha e que foi retomada na descrição do Raghuvamça da entrada de Aja e Indumatî" (70)

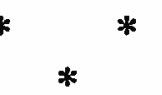

Como se pode verificar, são de variada natureza os recursos utilizados pelos estudiosos de Kâlidâsa para a sua datação: cronologias engenhosas, pilares, elogios textuais, imitação estilística, leitura obscura de termos, insinuações de ambigüidade semântica, tradições de outras culturas, biografias de poetas anteriores e posteriores, constatação de utilização de termos já tradicionais, etc. $\mathrm{Na}$ maior parte dos casos, as soluções adotadas são imprecisas, colocando o poeta "antes" ou "depois" dum século, na primeira ou na segunda metade de outros - e quase sempre sem atender unanimemente aos três fatores consagrados pela tradição popular

Com a atenção voltada, no entanto, para esta tradição, ficam eliminadas as tentativas de situá-lo nos séculos I a.C. e XI d.C.; deve-se considerá-lo, com certeza, posterior a Açvaghosa; em relação ao termo jâmitra, Keith concorda em que ele e outros foram "engenhosamente alterados para parecerem Sânscrito" (71) - a exemplo da "ingenuidade singular" verificada no metamorfoseamento de

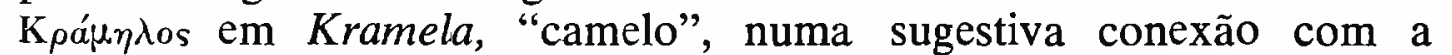
raiz KRAM, "ir" - e que os "empréstimos" tenham ocorrido talvez no ano 191 da era Çaka (72) (que começa no ano 78 d.C. o que colocaria o fato no ano 113 da era cristã) Se se toma como ponto de partida a data da sua morte - 522 d.C. - , aliado ao fato de o poeta ter abandonado Ujjayinî com a aproximação dos hunos (que destruíram aquela capital por volta de 510), tem-se um quadro bastante plausível das condições finais da sua vida. Por outro lado, a inscrição de Daçapura, "que imita versos de Kâlidâsa", pode localizar o poeta na primeira metade do século $\mathrm{V}$. ou um pouco antes, o que pode ser apoiado pelo trabalho do poeta junto à corte Vâkâtaka, que teria sido exercido entre os anos 390 e 410, época em que Prabhâvatîguptâ foi regente do trono herdado com a morte do seu marido (73) A inscrição de Aihole também pode favorecer essa possibilidade; Dinnâga, como registra a documentação budista, viveu no século VI - o que não contraria a eventualidade de sua contenda com Kâlidâsa ter ocorrido ainda no século $\mathrm{V}$, pois que Meghadûto passa por ter sido a penúltima obra composta pelo poeta.

(70) - Idem, ibidem, p. 91. FORMICHI, op. cit., pp. 35-36, enumera as estrofes: são as de número $13-23$ do livro III do Buddhacarita e 5-16 do canto VI do Raghuvamça.

(71) - Idem, ibidem, p. 25.

(72) - Idem, ibidem, pp. 530-531.

(73) - THAPAR,op. cit., p. 173. 
Isso posto - e já se deve admitir aí uma extrema longevidade para o poeta (mais ou menos 160 anos) —, Kâlidâsa poderia ter realmente vivido sob o reinado de vários Vikramâditya, como prefere considerar Vincent Smith, como Gema de vários Vikramâditya. Uma rápida verificação da genealogia dos Gupta imperiais, relativa ao período em questão, pode ser feita (74):

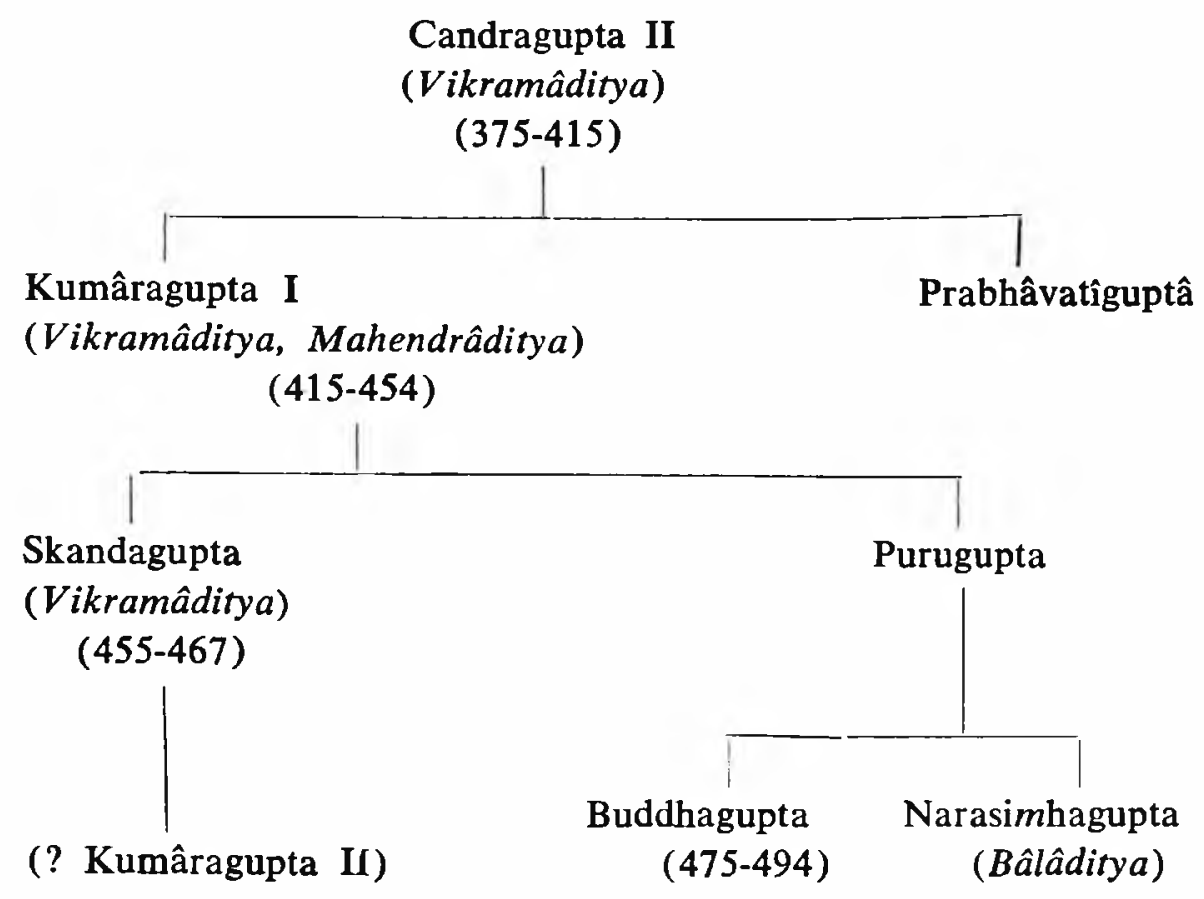

Nesse sentido, algum reparo deve ser feito em relação ao esquema apresentado por Sylvain Lévi, e que fundamenta a "hipótese Bhartrharí": Bâlâditya não é "filho de Vikramâditya", a não ser que se atribua a Purugupta - com base na afirmação de Margaret e James Stutley - o mesmo cognome e que se comprove que até os Gupta que não chegaram ao trono tenham merecido o seu uso.

Por outro lado, não se pode deixar de citar os argumentos que insistem na possibilidade da existência de muitos Kâlidâsa diferentes ao longo da história e da produção literária indiana. Kale informa

(74) - Extraída, no essencial, de The History and Culture of the Indian People. Bombay, Bharatiya Vidya Bhavan, 1954. Vol. III: The Classical Age. As datas foram extraídas de THAPAR, op. cit., passim, exceto para Buddhagupta, fornecidas por Jacques DUPUIS - Histoire de l'Inde. Paris Payot, 1963, p. 41. Não foi possível encontrar nenhuma data para o reinado de Bâlâditya; há, porém, a afirmação de KEITH, op. cit., p. 74, de que ele, aliado a Yaçovarman, expulsou os hunos em 528. 
que "pelo menos três deles eram conhecidos por Râjaçekhara" (75), poeta, teórico e comentador que viveu entre os séculos IX e X, que assim se expressou: na verdade "Um

vamos!

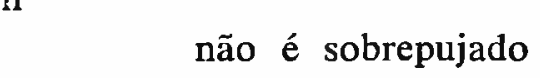
não é sobrepujado

Kalidâsa Na Erótica, quem é a tríade Kâlidâsa?” (76) no excelente discurso,

Kale afirma, ainda, que "por um, naturalmente, Râjacekhara se refere ao autor de Çakuntalâ, Raghuvamça, etc."

O certo é que o desenvolvimento e a interrogação de Râjaçekhara caíram no vazio desse reino do Talvez. E é Monier-Williams, ta!vez, quem coloca mais um espanto na questão: "parece que, em certo sentido, o termo kâlidâsa foi usado como um título honorífico" (77).

A ciência moderna, tanto a indiana quanto a ocidental, não tem medido esforços também com relação à identidade da terrra natal do poeta.

Em virtude da descrição que Kâlidâsa faz, no Meghadûta, da ciảade de Ujjayinî, Ingalls (78) supõe que ele teria nascido nas suas imediações; Kale (79) refere-se a "algum lugar da região de Mâlavâ" e talvez o local fosse Ujjayinî; Glasenapp (80) também faz uma referência ao distrito de Mâlavâ, hesitante entre Ujjayinî e Daçapura, "porque descreve esses dois lugares no Meghadûta"; Assier de Pompignan (81) transcreve a opinião de que ele seria "originário do Mandasor (= Daçapura), no Mâlavâ, e, em todo caso, na região de $\mathrm{Uj}$ jayinî"; Banerji (82) também cita Daçapura, mas alinha outras localidades que reclamam o berço do poeta: Caxemira, Vidarbha e Ceilão; Devadhar (83) afirma apenas que Ujjayinî "era a cidade do seu

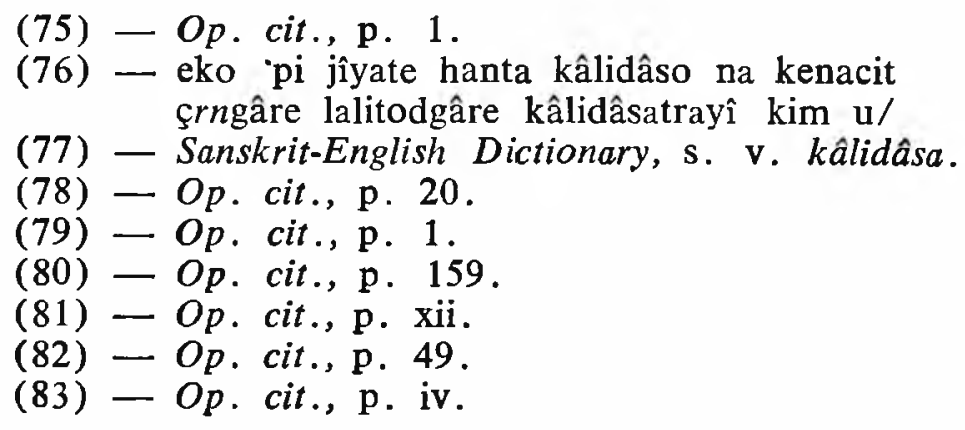


coração e ele tem o máximo prazer em cantar as suas glórias c os amores românticos das suas donzelas"

Por outro lado, afirma Glasenapp, ainda, que "bengalis patriotas tentaram provar, fundamentando-se em passagens isoladas da sua obra, que ele deve ser necessariamente seu compatriota"; entretanto, Keith (84) salienta que "mais engenhosa é a tentativa de fixar o seu lar na Caxemira e de tentar configurar a sua poesia como ilustração do Pratyabhijñânaçâstra daquela região, com a sua doutrina do reconhecimento da unidade do amor divino" Esse é o exercício de Lachhmi Dhar Kalla (referido também por Glasenapp), que afirma ser esta a razão de Kâlidâsa ser o poeta-mestre da sugestão (dhvani), que mais tarde se desenvolveu definitivamente na Caxemira como a essência da poesia.

2. e agora

\section{A biografia tradicional de Kâlidâsa}

Com propriedade nas metáforas com artifício na linguagem com dedicação aos valores mais tradicionais, a paixão tratada/traçada em sua sensualidade; na Índia só no nome de Kâlidâsa da poesia clássica a perfeição.

Nasceu no Mâlavâ, no seio duma família de casta bramânica . O seu pai, um bráhman - um homem religioso, versado no conhecimento sagrado dos textos védicos, mais culto que as outras três sortes de sacrificantes, piedoso, dotado de excelsas virtudes, amigo da Ordem e da Verdade, semelhante ao próprio Brahmán em pessoa, guardião da sílaba sagrada .

Nem pronunciara ainda as primeiras sílabas: ficou órfão aos seis meses de idade. Foi recolhido, adotado e criado por um boieiro. Não recebeu nenhuma educação sistemática, crescendo absolutamente afastado da presença dum sábio ou mestre. Uma adolescência mergulhada na mais extrema ignorância. Jovem, um rematado idiota. A sociedade que o viu crescer em nada elevou a sua distinção natural. Errou pelas estradas com o gado até que um dia chegou a Vârânasî.

Acontecia que, naquele tempo, Bhîmaçukla reinava em Vârânasî. A sua filha, a princesa Vasantî, em idade de se casar, desejava que seu esposo fosse um homem versado nas ciências e nas artes. Os pretendentes à sua mão eram numerosos: a formosura, a digni-

(84) - Op. cit., p. $\mathrm{x}$. 
dade, a fortuna e a graça da princesa haviam atraído ao seu svayamvara uma plêiade de homens cultos, garbosos, refinados, orgulhosos, gabolas. A princesa os rejeitou a todos. Desdenhou, por não ser támbém do seu agrado, a Vararuci, ministro do seu real pai.

Vararuci, hábil em artimanhas, incapaz de conservar oculta no coração a ira que o dominava, jurou vingar-se da pretendida desd?nhadora. Numa manhã, circulando pela cidade, viu no mercado de gado um jovem boieiro, extremamente belo em seu gibão de couro, a encarnação viva de Kandarpa, o deus Amor. A sua vingança mate_ rializava-se ali, diante dos seus olhos. Concebeu-lhe, arquitetou-lhe um plano.

Alguns dias depois, o jovem estava presente na coluna de pretendentes: instruído por Vararuci, estava vestido como um sábio, cercado de pânditas que se diziam seus discípulos. Uma mudez absoluta aureolava o jovem mestre; os seus discípulos enalteciam as suas riquezas: os seus domínios, a sua sabedoria. A beleza era visível.

Um silêncio absoluto tomou conta da princesa: estava ali o homem dos seus sonhos e desejos, o amante e senhor. Ela era uma pérola entre as mulheres; ele, um ilustre filósofo. A sua união haveria de ser frutuosa.

Encantada, a princesa tomou-lhe a fímbria do manto e, deste modo, indicou aos presentes ser ele o noivo escolhido. Alegrou-se Bhîmaçukla, felicitaram-na os pretendentes, exultou Vararuci. A orgulhosa princesa e o ignorante boieiro estavam totalmente subjugados pela esperteza do ministro.

Celebrou-se o casamento com a maior solenidade. As pompas duraram alguns dias. O boieiro recém-feito príncipe a tudo assistia atônito; a princesa estava mergulhada na sua satisfação; os convidados não se cansavam de exaltar a magnificência de Bhîmaçukia, a beleza da sua filha e a sabedoria muda do eleito. Vararuci ainda aguardava novos lances.

Duraram alguns dias as pompas. Num deles, a princesa levou o esposo e senhor a conhecer as dependências do palácio. O gineceu, os balanços, o solário, o teatro com os camarins, as cortinas e os instrumentos dos músicos; os incontáveis quartos e salas, os painéis nas paredes, as torres e os tetos dourados pelo Sol e prateados pela Lua. O jardim, os repuxos, os caramanchões, os tanques com lótus desabrochados e de garças e de cisnes enfeitados. A tudo a jovem pontilhava de detalhes; a tudo o jovem prestava a sua muda atenção. Súbito, quando estavam no templo, o jovem pára diante duma estátua que representava um touro e elogia o trabalho do artista: 
- Muinto paricidu mermo, inguarzinhu us meu.

À princesa sânscrita, atônita e estupidificada, o jovem relata, simplória e detalhadamente, a sua história. No prácrito rude e desordenado que aprendera. A princesa, furiosa, ferida no seu orgullho, ameaça revelar-lhe a origem a todos; expulsá-lo da Corte depois de o fazer sofrer duros castigos. O jovem suplica-lhe, implora-lhe clemência, a graça da sua generosidade. A princesa, rendida pelo amor que ele despertara no seu coração, aconselha_o a adorar a deusa Kâlî para dela obter alguma parcela de inteligência, condição do seu perdão. Ali mesmo, no mesmo momento, o jovem dá início a uma severa penitência, oferecendo à terrível deusa a sua cabeça, o seu gênio futuro. Propiciou-a com oferendas, recitações, purificações. Kâlî, finalmente conciliada,deu-lhe o dom da poesia, a prodigiosa erudição. Para a deusa o seu corpo, o seu espírito e os seus sentimentos: daquele momento em diante passaria a ser Kâlidâsa, o escravo de Kâlî. Para a esposa, o imprudente juramento de ser o seu guru, o seu mestre espiritual .

O seu esposo e senhor devotava-se-lhe como a uma pessoa sagiada. O respeito que esse título impunha ao casal pareceu-lhe exorbitante; descontente com esse excesso de honra, que a privava dos prazeres permitidos, ela desejou que Kâlidâsa morresse pelas mãos duma mulher. Muito discretamente, como o futuro aprouvesse.

Em breve, a sua marcada habilidade na pronta feitura de versos ou para descrever uma situação qualquer e, principalmente, para completar uma estrofe iniciada por outro poeta, granjeou-lhe a posição de poeta ilustre em Vârânasî. Um dia é informado de que o rei Vikramâditya, de Ujjayinî, a capital do reino, fará realizar mais um concurso de poesia. Transfere-se para lá. Já tem na sua bagagem o seu Rtusamhâra, obra primeira, de juventude, em que colegas criticam muitos senões. "As críticas, lótus noturnos florescidos durante o dia" — julga-os poetas do alto da sua habilidade poética.

Ujjayinî haveria de ser a corte do seu coração. Çivaíta o poeta, centro çivaíta de peregrinação a cidade; além disso, era ela a capital, ali estava a Corte dominante do seu país. Mais e melhor que em outro lugar, ele ali exercitaria e exerceria o seu gênio.

Muitos foram os inscritos para o concurso. Dentre eles, o que se revelou o mais temível foi um que arrogantemente proclamava:

- Por mim a poesia é feita para os concorrentes vencer. Pelo amor da minha mãe eu juro: "se no emprego do duplo sentido por um outro poeta eu for vencido, então com um cântaro gretado água carregarei!" 
Era este o tema do concurso: ghatakarpara - "cântaro gretado", mas também "nuvem" No dia aprazado para o julgamento dos trabalhos, o salão estava lotado pela corte de Ujjayinî e pelas cortes menores de todo o reino. Os poetas declamaram os seus poemas, a platéia foi unânime: o de Kâlidâsa era o mais per-feito, o seu estilo poético era o mais bem elaborado, o autor demonstrava o seu conhecimento profundo de todos os tratados de poética a sua expressão era límpida e brilhante, os seus versos eram harmoniosos, preciosamente polidos. o jovem poeta era sóbrio no emprego das figuras de som e de sentidn, poderosamente rico nas comparações.

O poeta foi aclamado unanimemente e incluído no conjunto das Gemas da corte. O seu poema, porém, resitado aqui e ali nos palácios da Corte, não mereceu registro e desapareceu na memória dos que lhe souberam os encantos. Quanto àquele arrogante, obscuro e feroz candidato aos favores do rei, que desafiara todos os outros conccrrentes: ao poeta restou cumprir o juramento, ao poema a glória da sua fixação, ao poeta e ao poema o estigma de "cântaro gretado" $O$ seu poema falava de uma jovem esposa que, no começo da estação aas chuvas, enviava uma mensagem por uma nuvem ao seu marido ausente. O futuro ainda daria a Ghatakarpara um lugar entre as Gemas da Corte; daria também, só que a Kâlidâsa, o ensejo de elaborar um poema com o mesmo motivo e uma nova vitória sobre aquele espalhafatoso poeta.

A vida de Kâlidâsa na Corte corria plácida, prestigiada e faustosa. Kâlidâsa submetia-se serenamente aos prazeres e obrigações que o cargo lhe impunha: a sua habilidade poética nos freqüentes torneins literários propiciava-lhe a fama buscada, o luxo desejado, a Ventura inebriante. Em Ujjayinî passaria a maior parte da sua vida: estróina elegante, estrela radiante, libertino refinado, esperto e espirituoso, genialidade transbordante e ativo sempre. Conhecia a fundo o mundo mundano da Corte, as pessoas e os seus ambientes. Mas não conhecia menos o fundo sagrado da filosofia e da religião do seu povo: os textos dos Veda, das Upanisad, os Purâna, o Kâmasûtra. Era simpático a todas as seitas, sem fanatismo por nenhuma em especial. E manejava o Sânscrito como nenhum outro na sua época.

Nas festas de uma primavera, em Ujjayinî, o diretor da peça representada naquela ocasião adentra o palco e assim se expressa, algo empolgado:

- Por esta platéia fui encarregado de este drama fazer representar para esta festa do início da primavera. Mâlavikâgnimitra é o seu título, Kâlidâsa o seu autor . 
- Mas por que tanta admiração - indaga-lhe a sua auxiliar-de-direção — pelo contemporâneo poeta Kâlidâsa, os famosos Bhâsa, Saumilla, Kaviputra, etc. deixando de lado?

- Não digas bobagens. Ouve: "Nenhum poema é belo por ser antigo, nem por ser novo deve ser desprezado. Os honestos examinam e escolhem, o tolo julga sempre segundo um outro."

Concluída a representação dos dissabores da princesa Mâlavikâ e do príncipe Agnimitra e festejada a vitória dos seus sentimentos, a platéia novamente aclamou o gênio do seu autor Alguns anos depois, por ocasião da encenação de Çakuntalâ, outro será o comportamento do diretor e da atriz que com ele contracena no prólogo:

- Temos aqui um público atento. E devemos representar-lhe o novo drama de Kâlidâsa, intitulado Çakuntalâ reconhecida. Por isso recomendo que cada um de vós coloque o devido empenho no seu papel.

- Em obediência às sábias disposições dadas por Vossa Senhoria, nada será descuidado na representação.

Antes de Çakuntalâ, o poeta escrevera o seu segundo drama, $V i$ kramorvacîya, em que faz reviver no palco o tradicional amor do rei Pururavas pe!a ninfa Urvaçî. Logo após Çakuntalâ escreverá as três primeiras partes do seu Raghuvamça; abandonará o trabalho para escrever o seu primeiro poema épico completo, o Kumârasambhava. Após ele, o motivo do poema de Ghatakarpara voltará à sua memória e ele escreverá o seu Meghadîta, poema elegíaco em que um príncipe, no exílio no sul do país, envia à amada, no Norte, uma mensagem por intermédio duma nuvem. Após esse poema, retomará o seu Rag'ıu$v a$ m̧̧a, que ficará inacabado. Entre essas obras-primas o poeta escreverá muitas outras menores; mas são as grandes que consagrarão definitivamente o seu gênio.

Kâlidâsa viajou por todo o país - seja em missões especiais designadas por Vikramâditya, seja para abrilhantar as cortes com a sua arte. Conheceu as palmeiras de Bengala, os coqueiros e o bétele de Kalinga, as pérolas de Tâmraparnî, o sândalo da Caxemira, a pimenta e o cardamono do Malabar, os cedros do Himalaia, as areias do rio Indo; o oceano, que "a cada momento parece novamente novo aos olhos de alguém", e as suas baleias; os persas barbados e os seus gibões e elmos; a antiga capital, Vid'çâ, e as grutas nas montanhas onde as prostitutas exerciam o seu comércio; o grande templo de Kumâra em Daçapura; os âçrama, antídotos para a vida na Corte. 
O itinerário poético da sua nuvem-mensageiro é estabelecido com precisão geográfica; como também é precisa a informação de que as esposas dos chefes hunos - que ameaçavam as fronteiras do noroeste - praticavam o kapolapâtanadeçî, "costume dos arranhões na face" para ficarem belas. Foi enviado, também, à corte Vâkataka, onde se tornou o tutor de Pravarasena, filho de Prabhâvatîguptâ e do rei Rudrasena II, dinasta e senhor daquela região morto logo depois de subir ao trono.

Certa vez os hunos penetraram mais seriamente reino Gupta a dentro. Ameaçavam invadir Ujjayinî. Já as defesas da capital se aprestavam para a sua defensão quando Kâlidâsa recebe um convite de Kumâradâsa, rei do Ceilão, seu dileto amigo. Depois duma vida superlativamente romântica, e com a guerra às portas da cidade, Kâlidâsa apressa-se e parte. E recebido com todas as honras que deveriam ser feitas ao maior poeta da época.

Uma noite, numa festa realizada na vivenda duma das cortesãs, o rei Kumâradâsa - também ele um habilidoso poeta - escreve numa parede os seguintes versos:

"Uma flor brotada sobre outra flor:

coisa ouvida mas jamais vista",

prometendo um prêmio a quem escrevesse dois outros que os completassem.

Kâlidâsa, no seu canto e nos braços da anfitriã, murmura em voz baixa os exercícios de composição dos dois versos. Logo os tem, mas - como mero hóspede - aguarda que um outro poeta os componha. Entre um carinho e outro, no entanto, confidencia-os à mulher que o afaga. E o assassina com uma punhalada, os gritos sufocados por mais um beijo. Ela arrasta o cadáver para fora do salão, esconde-o num buraco cavado no chão de um dos quartos; volta à reunião, dá uma desculpa qualquer. O desafio ainda não tem um vencedor. Pede permissão a Kumâradâsa para declamar o seu trabalho, que os presentes ouvem deliciados:

"E então, mocinha, a que pretexto

dois lótus no lótus do teu rosto?"

Ela recebe o prêmio. Mas Kumâradâsa, rememorando os versos vencedores, reconhece neles o gênio do amigo Kâlidâsa. Estranhando a sua demora, e já suspeitando da inveja da, cortesã e do que eỉa poderia ter feito para se apoderar do prêmio, ordena que toda a casa seja revistada à procura do poeta. Não o encontram. O amigo, 
desesperado, ordena que toda a casa seja escavada: o cadáver do poeta é encontrado.

$\mathrm{Na}$ tarde do dia seguinte, Kumâradâsa atira-se ao fogo da pira em que ardia o cadáver do amigo Kâlidâsa (85)

\section{BIBLIOGRAFIA}

ALVIELLA, Goblet d' - Ce que l'Inde doit à la Grèce. Paris, Paul Geuthner, 1926.

ASSIER DE POMPIGNAN, R. H. - Meghadûta/Rtusamhâra. Paris, "Les Belles Lettres”, 1938 (2ạ tiragem, 1967)

BANERJI, Sures Chandra - A Companion to Sanskrit Literature. Delhi, Motilal Banarsidass, 1971.

DEVADHAR, C. R. - Abhijñânasakuntalam of Kâlidâsa. Delhi, Motilal Banarsidass, 1934 (3ạ reimpr. 1972).

DEVADHAR, C. R. - Mâlavikâgnimitram of Kalidâsa. Delhi, Motilal Banarsidass, 3ạ ed. (reimpr. 1977).

DUPUIS, Jacques - Histoire de l'Inde. Paris, Payot, 1963.

FORMICHI, Carlo - Kalidasa: la stirpe di Raghu. Milano, Istituto Editoriale Italiano, s. d.

GLASENAPP, H. de - Les littératures de l'Inde. Paris, Payot, 1963.

GUBERNATIS, Angelo de - Letteratura indiana. Milano, Hoepli, 1883.

HERRY, Victor - Les littératures de l'Inde. Paris, Hachette, 1904.

History and Culture of the Indian People, The. - Bombay, Bharatiya Vidya Bhavan, 1954. Vol. III: The Classical Age.

INGALLS, Daniel H. H. - "Kâlidâsa and the Attitudes of the Golden Age". In Journal of the American Oriental Society. Vol. 1, 96, $\mathrm{n}^{\circ}$ 1, janmar 1976.

KALE, M. R. - Kiratârjunîyam, cantos I-IH. Delhi, Motital Banarsidass, 1966 (reimpr. 1977)

KALE, M. R. - The Ritusamhara. Delhi, Motilal Banarsidass, 1916 (2a ed. 1967).

(85) - Esta "biografia tradicional" foi elaborada com base em todas as informações, fornecidas pelos autores constantes da bibliografia anexa, referidas como abonadas pelas tradições indianas e cingalesas, bem como testemunhos extraídos da própria obra de Kâlidâsa. 
KEITH, A. Berriedale - A History of Sanskrit Literature. London, Oxford University Press, 1920 (reimpr. 1961).

LÉVI, Sylvain - Le théatre indien. Paris, Honoré Champion, 1890 (2ạ tiragem 1963)

MACDONELL, Arthur A. - A History of Sanskrit Literature. New York, Haskell House, 1900 (reimpr. 1968).

MONIER-WILLIAMS, Monier - Sanskrit-English Dictionary. Oxford, Clarendon Press, 1974 (reimpr. da 1ạ ed., 1899).

MONIER-WILLIAMS, Monier - English-Sanskrit Dictionary. Delhi, Motilal Banarsidass, 1956 (reimpr.)

PISANI, Vittore - Kalidasa. Cernusco sul Naviglio, Garzanti, 1946.

STERNBACH, Ludwig - "A propos de petits recueils de vers gnomiques". In Journal Asiatique, tomo CCLXII, 1974, fasc. 3/4.

STUTLEY, Margaret e STUTLEY, James - A Dictionary of Hinduism. Lon. don, Routledge-Kegan Paul, 1977.

THAPAR, Romila - Historia de la India. I. México, Fondo de Cultura Económica, 1969.

TUBINI, Bernadette - Kâlidâsa: la naissanse de Kumâra. Paris, Gallimard. 1958, 5ạ ed. 